In the format provided by the authors and unedited.

\title{
Covalent binding of uracil DNA glycosylase UdgX to abasic DNA upon uracil excision
}

Woo-Chan Ahn',2, Shashanka Aroli, Jin-Hahn Kim4, Jeong Hee Moon', Ga Seal Lee', Min-Ho Lee', Pau Biak Sang ${ }^{3}$, Byung-Ha Oh $\oplus^{2}$, Umesh Varshney ${ }^{3 \star}$ and Eui-Jeon Woo $\circledast^{1,5 \star}$

'Disease Target Structure Research Center, Korea Research Institute of Bioscience and Biotechnology, Daejeon, Republic of Korea. ${ }^{2}$ Department of Biological Sciences, KAIST Institute for the Biocentury, Korea Advanced Institute of Science and Technology, Daejeon, Korea. ${ }^{3}$ Department of Microbiology and Cell Biology, Indian Institute of Science, Bangalore, India. ${ }^{4}$ Creative Research Initiative Center for Chemical Dynamics in Living Cells, Department of Chemistry, Chung-Ang University, Seoul, Korea. ${ }^{5}$ University of Science and Technology, Daejeon, Republic of Korea. ${ }^{\star}$ e-mail: varshney@iisc.ac.in; ejwoo@kribb.re.kr 
Supplementary Table 1. Data collection and refinement statistics (molecular replacement)

\begin{tabular}{|c|c|c|c|c|c|c|}
\hline & Apo-UdgX & $\begin{array}{l}\text { UdgX-5mer } \\
\text { ssDNA }\end{array}$ & UdgX-UMP & UdgX-uracil & $\begin{array}{l}\text { UdgX-H109S } \\
\text { mutant }\end{array}$ & $\begin{array}{l}\text { UdgX-E52Q } \\
\text { mutant }\end{array}$ \\
\hline \multicolumn{7}{|l|}{ Data collection } \\
\hline Space group & $\mathrm{P} 2$ & P222 & $\mathrm{P} 2$ & $\mathrm{P} 2$ & $\mathrm{P} 2$ & $\mathrm{P} 2$ \\
\hline \multicolumn{7}{|l|}{ Cell dimensions } \\
\hline$a, b, c(\AA)$ & $36.32,51.64,54.36$ & $\begin{array}{l}36.83,64.45 \\
82.90\end{array}$ & $\begin{array}{l}36.44,51.21 \\
54.53\end{array}$ & $\begin{array}{l}36.48,51.77, \\
55.11\end{array}$ & $\begin{array}{l}36.22,51.39 \\
55.44\end{array}$ & $\begin{array}{l}36.40,51.60 \\
54.44\end{array}$ \\
\hline$\alpha, \beta, \gamma\left({ }^{\circ}\right)$ & $90.00,105.31,90.00$ & $\begin{array}{l}90.00,90.00 \\
90.00\end{array}$ & $\begin{array}{l}90.00,104.98 \\
90.00\end{array}$ & $\begin{array}{l}90.00,104.98 \\
90.00\end{array}$ & $\begin{array}{l}90.00,105.21 \\
90.00\end{array}$ & $\begin{array}{l}90.00,105.35 \\
90.00\end{array}$ \\
\hline Resolution $(\AA)$ & $\begin{array}{l}50.00-1.314(1.36-1.34) \\
*\end{array}$ & $\begin{array}{l}50.00-2.28(2.32- \\
2.28)\end{array}$ & $\begin{array}{l}50.00-1.33(1.35- \\
1.33)\end{array}$ & $\begin{array}{l}50.00-1.34(1.36- \\
1.34)\end{array}$ & $\begin{array}{l}50.00-1.63(1.66- \\
1.63)\end{array}$ & $\begin{array}{l}50.00-1.34(1.36- \\
1.34)\end{array}$ \\
\hline$R_{\text {merge }}$ & $0.077(0.187)$ & $0.098(0.938)$ & $0.057(0.153)$ & $0.054(0.238)$ & $0.063(0.129)$ & $0.061(0.383)$ \\
\hline$I / \sigma I$ & $56.32(18.20)$ & $31.21(1.7)$ & $47.76(5.00)$ & $54.35(10.33)$ & $56.00(28.67)$ & $33.05(4.64)$ \\
\hline Completeness (\%) & $96.2(86.1)$ & $99.0(86.1)$ & $96.9(68.3)$ & $97.7(98.4)$ & $97.4(92.0)$ & $96.7(98.2)$ \\
\hline Redundancy & $7.5(6.6)$ & $11.9(8.2)$ & $6.8(5.5)$ & $6.9(5.9)$ & $6.2(5.9)$ & $3.3(3.0)$ \\
\hline \multicolumn{7}{|l|}{ Refinement } \\
\hline Resolution $(\AA)$ & 1.34 & 2.28 & 1.33 & 1.34 & 1.63 & 1.34 \\
\hline No. reflections & 42199 & 8569 & 43193 & 43379 & 23412 & 14956 \\
\hline$R_{\text {work }} / R_{\text {free }}$ & $13.3 / 16.0$ & $19.4 / 26.5$ & $17.2 / 18.6$ & $13.84 / 16.57$ & $15.99 / 19.71$ & $17.34 / 19.33$ \\
\hline \multicolumn{7}{|l|}{ No. atoms } \\
\hline Protein & 1539 & 1501 & 1531 & 1532 & 1538 & 1563 \\
\hline Ligand/ion & 8 & 21 & 28 & 16 & 8 & 8 \\
\hline Water & 190 & 15 & 244 & 299 & 216 & 250 \\
\hline$B$-factors & 15.05 & 54.17 & 20.60 & 20.15 & 24.62 & 20.71 \\
\hline Protein & 14.06 & 52.79 & 19.04 & 17.23 & 23.48 & 18.95 \\
\hline Ligand/ion & 8.1 & 54.80 & 20.11 & 13.02 & 16.48 & 12.3 \\
\hline Water & 23.41 & 51.59 & 30.41 & 35.51 & 33.09 & 31.97 \\
\hline \multicolumn{7}{|l|}{ R.m.s. deviations } \\
\hline Bond lengths $(\AA)$ & 0.007 & 0.019 & 0.008 & 0.007 & 0.007 & 0.007 \\
\hline Bond angles $\left({ }^{\circ}\right)$ & 0.92 & 1.9 & 1.11 & 0.89 & 0.94 & 0.93 \\
\hline
\end{tabular}

Each dataset was collected from a single crystal. *Values in parentheses are for highest-resolution shell. 

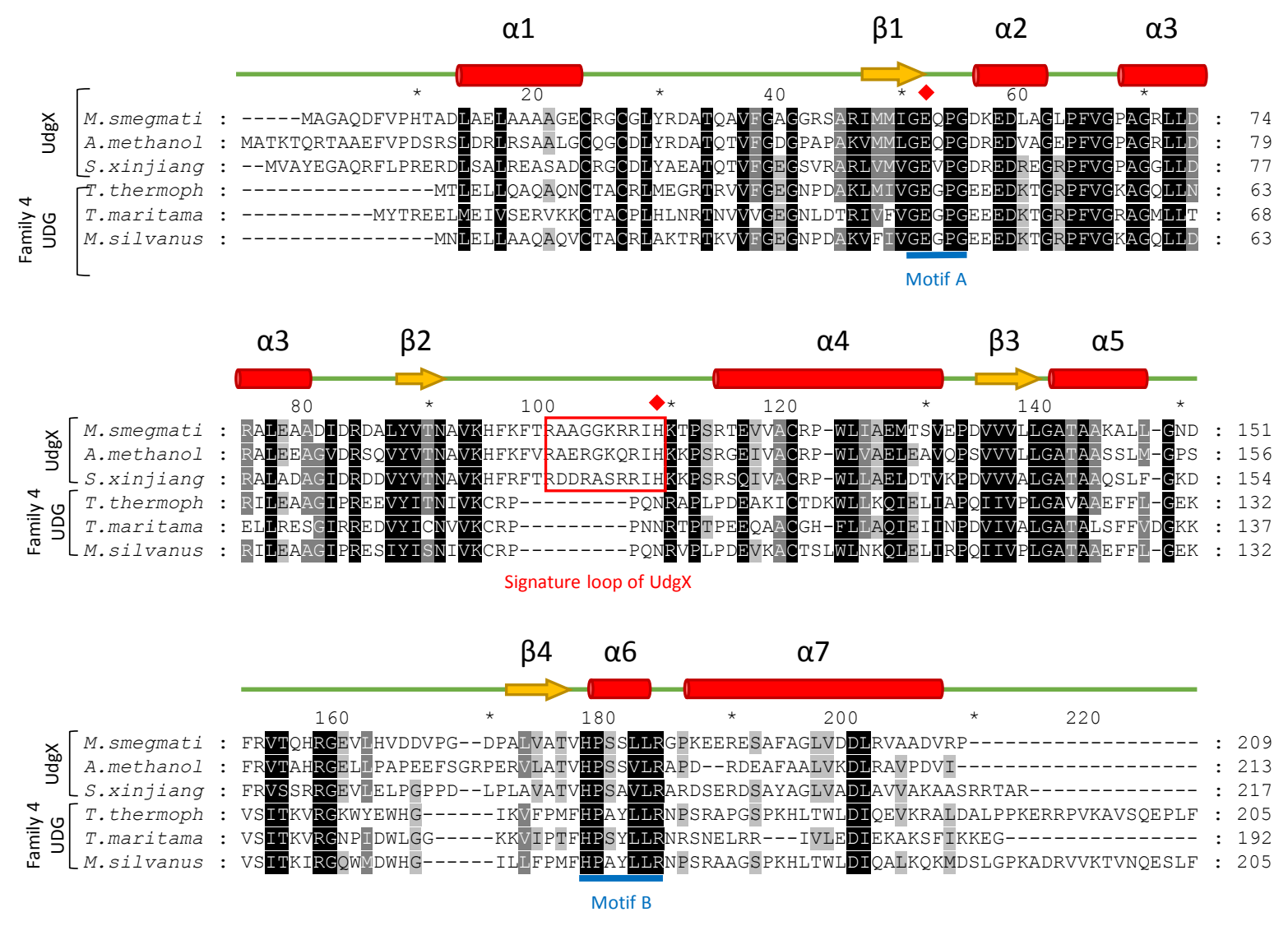

\section{Supplementary Figure 1}

Multiple sequence alignment of MsmUdgX proteins with other UdgXs and Family 4 UDGs from other bacteria and the secondary structure of MsmUdgX protein. The signature motif UdgX is highlighted with a red box. Conserved motifs $A$ and $B$ are underlined in blue. Residues involved in the catalytic dyad are indicated with red diamonds. Black, dark gray, and light gray shading indicates residues that are conserved in $6 / 6,5 / 6$, and $4 / 6$ of proteins, respectively. Accession numbers for these sequences are WP_011726794.1 (UdgX from $M$. smegmatis), WP_017983848.1 (UdgX from A. methanolica), WP_006237039.1 (UdgX from S. xinjiangensis), WP_011228142.1 (family4 UDG from $T$. thermophilus), WP_004081422.1 (family 4 UDG from $T$. maritama), and WP_013158605.1 (family 4 UDG from M. silvanus). 


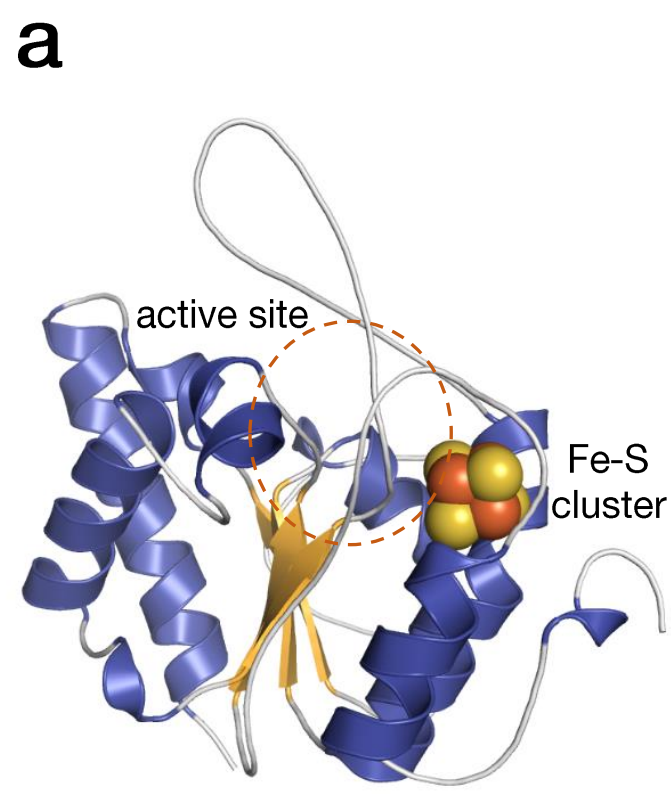

b

\section{C}

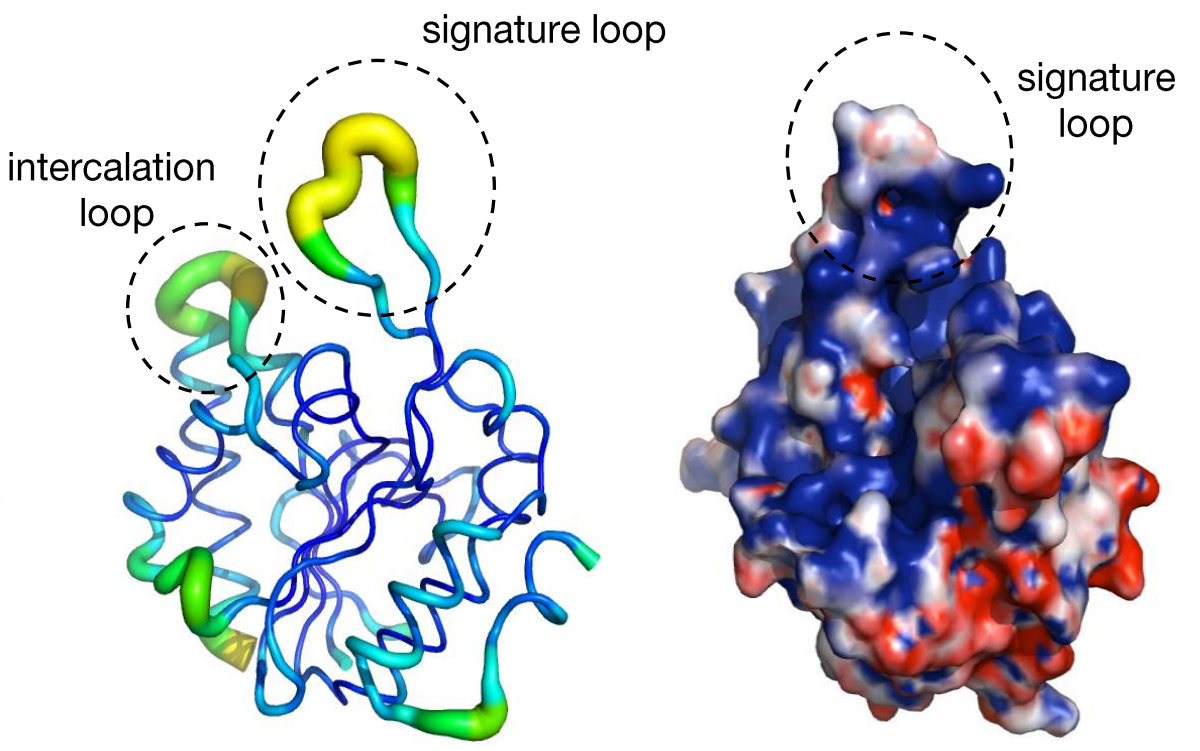

\section{Supplementary Figure 2}

(a) Side view of MsmUdgX structure emphacizing $\alpha / \beta / \alpha$ sandwich folding. The $\alpha$-helices and $\beta$ strands are colored in blue and yellow, respectively. (b) B-factor putty presentation of the MsmUdgX apo-form structure. The wide yellow ribbon represents a higher b-factor compared to the thin blue ribbon with lower b-factor. (c) Electrostatic surface potential (scale of -10 to $+10 \mathrm{kTe}-1$ ) of the apo form of MsmUdgX. Acidic and basic regions are colored in red and blue, respectively. 


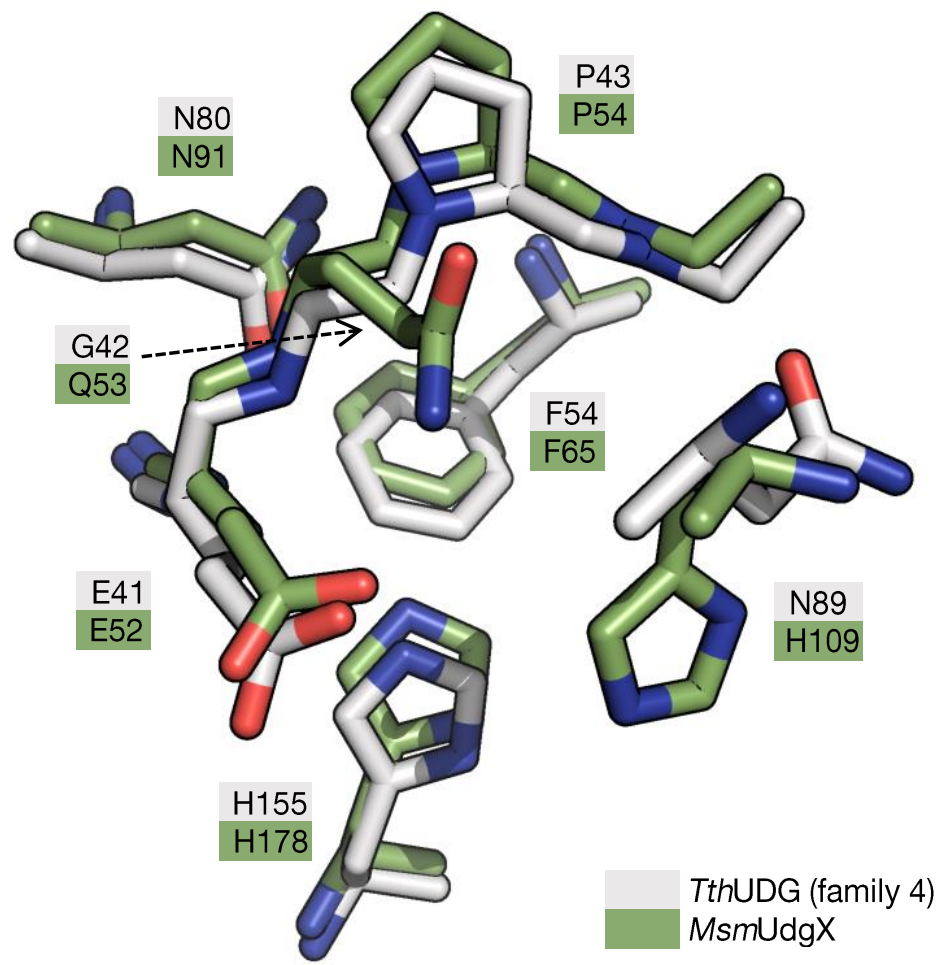

Supplementary Figure 3

Overlap of conserved residues in active site illustrates high similarity in the uracil-binding site of TthUDG (white) and MsmUdgX (green) and highlights substitution of water-activating residue N89 in TthUDG by H109 in MsmUdgX (green). 


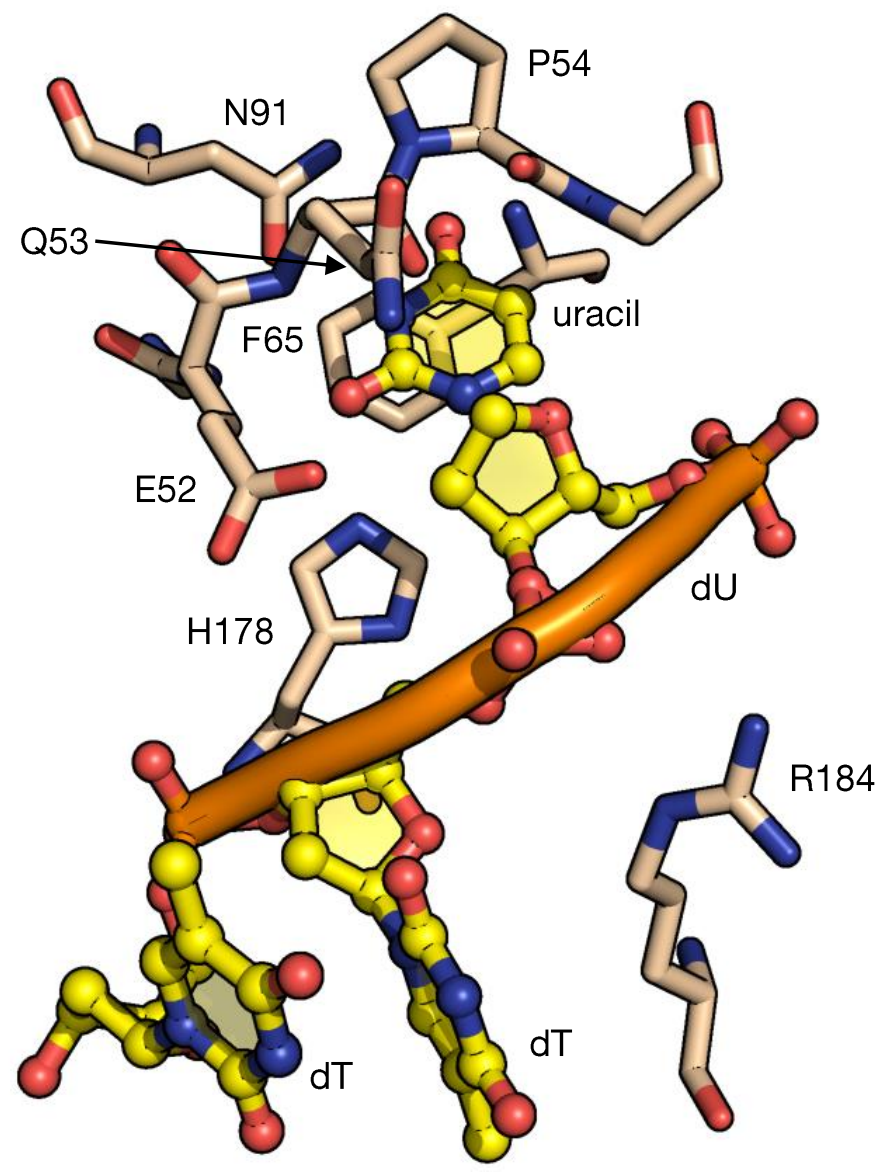

Supplementary Figure 4

Deoxyuridine residue with flipped geometry in the active site of MsmUdgX (presented with yellow sticks and spheres). Conserved residues in the active site, E52, Q53, P54, F65, N91, $\mathrm{H} 178$, and R184, are shown with wheat-colored sticks. 
Human UDG (family 1)

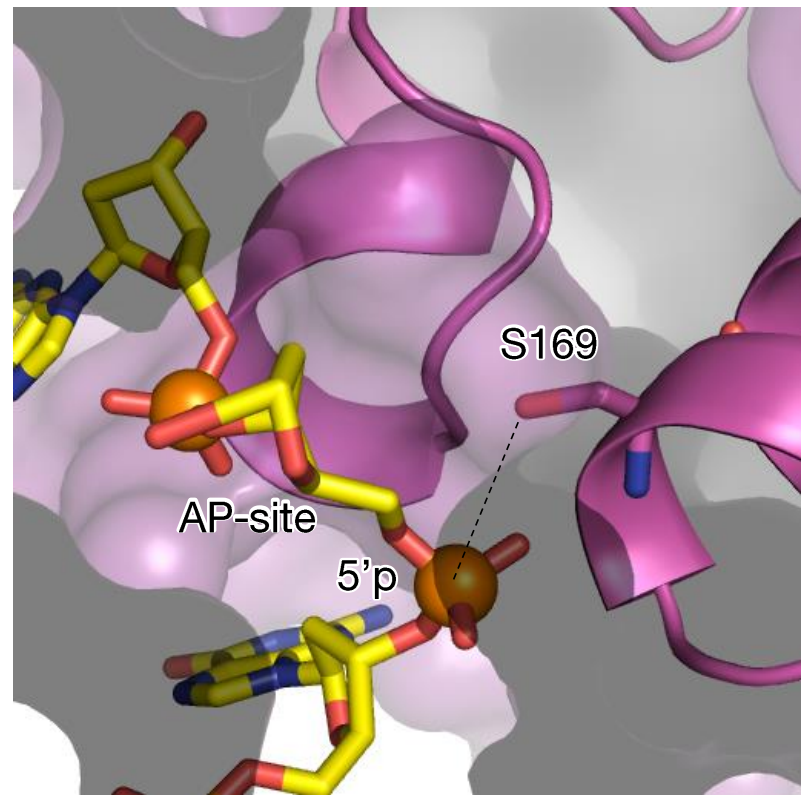

MsmUdgX

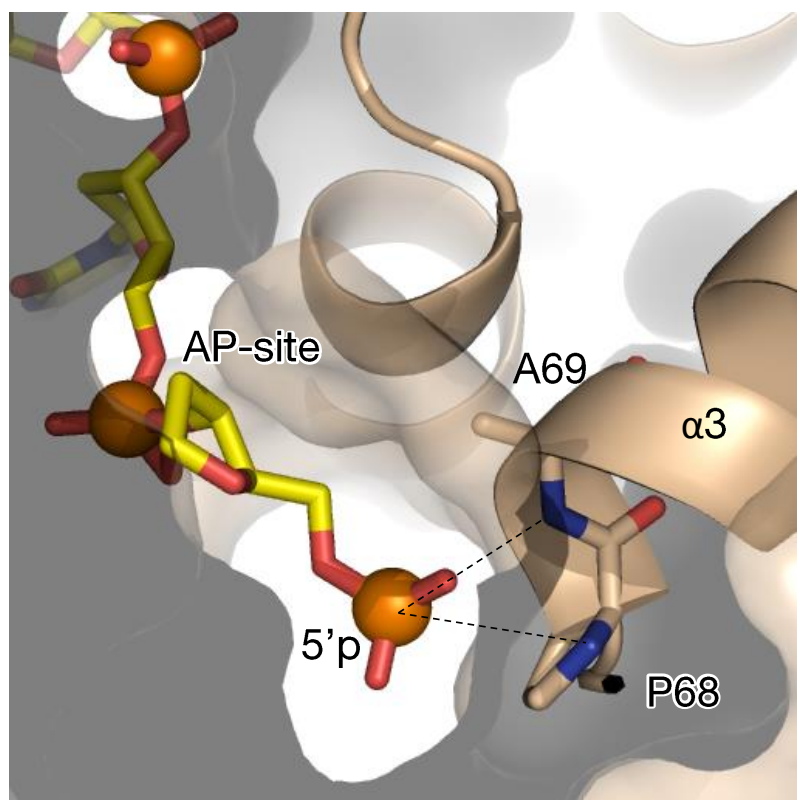

\section{Supplementary Figure 5}

Interaction with the phosphate (orange spheres) which is 5 ' to deoxyuridine in family 1 human UDG (left) and MsmUdgX (right). 


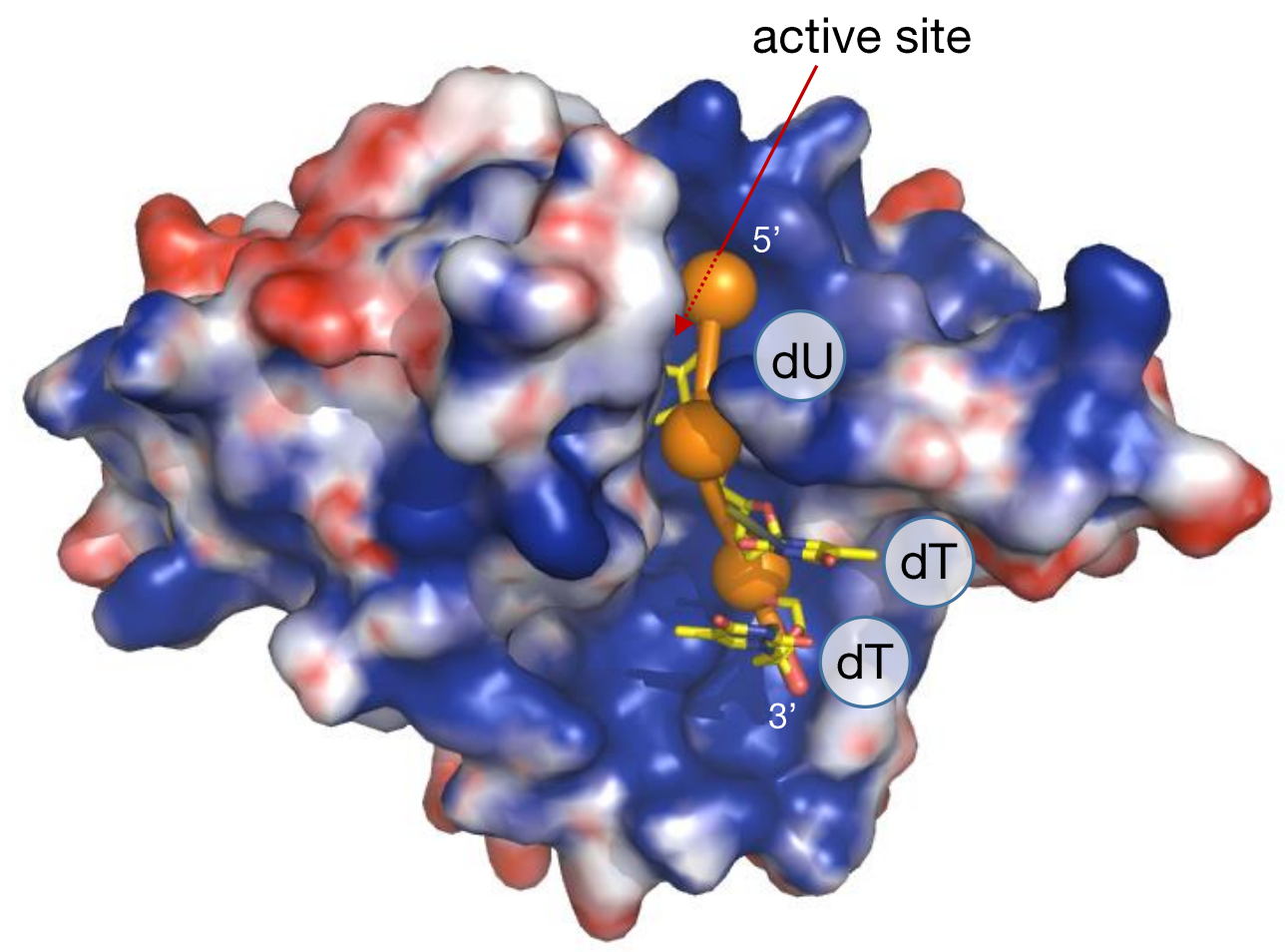

\section{Supplementary Figure 6}

Interaction between backbone phosphate of 5mer ssDNA and positive surface of MsmUdgX. Backbone phosphates (orange spheres) observed in the MsmUdgX-5mer DNA complex interact with the positively charged surface of MsmUdgX. Electrostatic surface potential is calculated at scale of -10 to $+10 \mathrm{kTe}-1$ and colored red and blue for acidic and basic regions, respectively. 


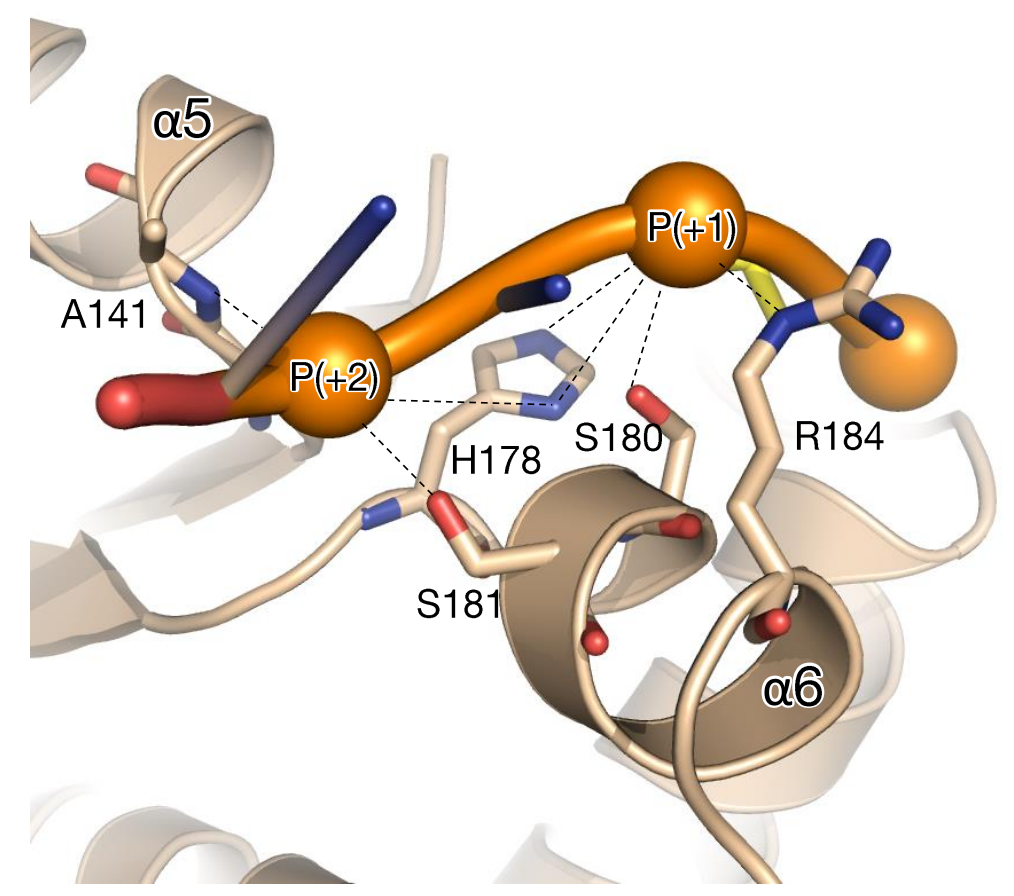

Supplementary Figure 7

Hydrogen bonding interactions (dashed line) of MsmUdgX with the phosphate, 3' to deoxyuridine (labeled $\mathrm{P}(+1)$ ) and the next phosphate (labeled $\mathrm{P}(+2)$ ). 


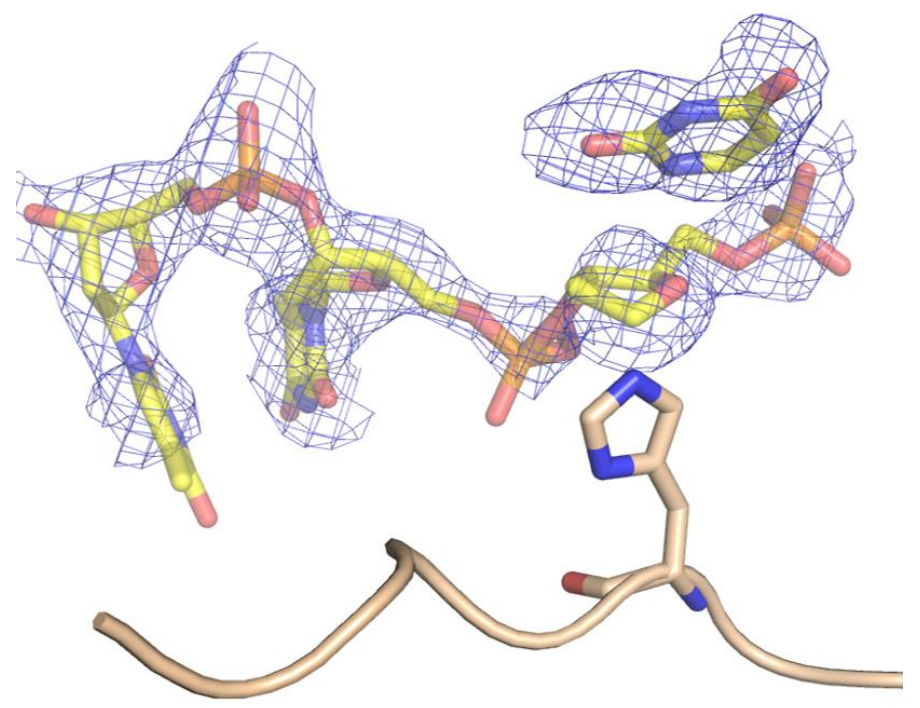

Supplementary Figure 8

The $F_{O}-F_{C}$ electron density map around the ligand in the structure of MsmUdgX and uracil containing $5 \mathrm{mer}$ ssDNA. The density map is contoured at the $2.0 \sigma$ level. 


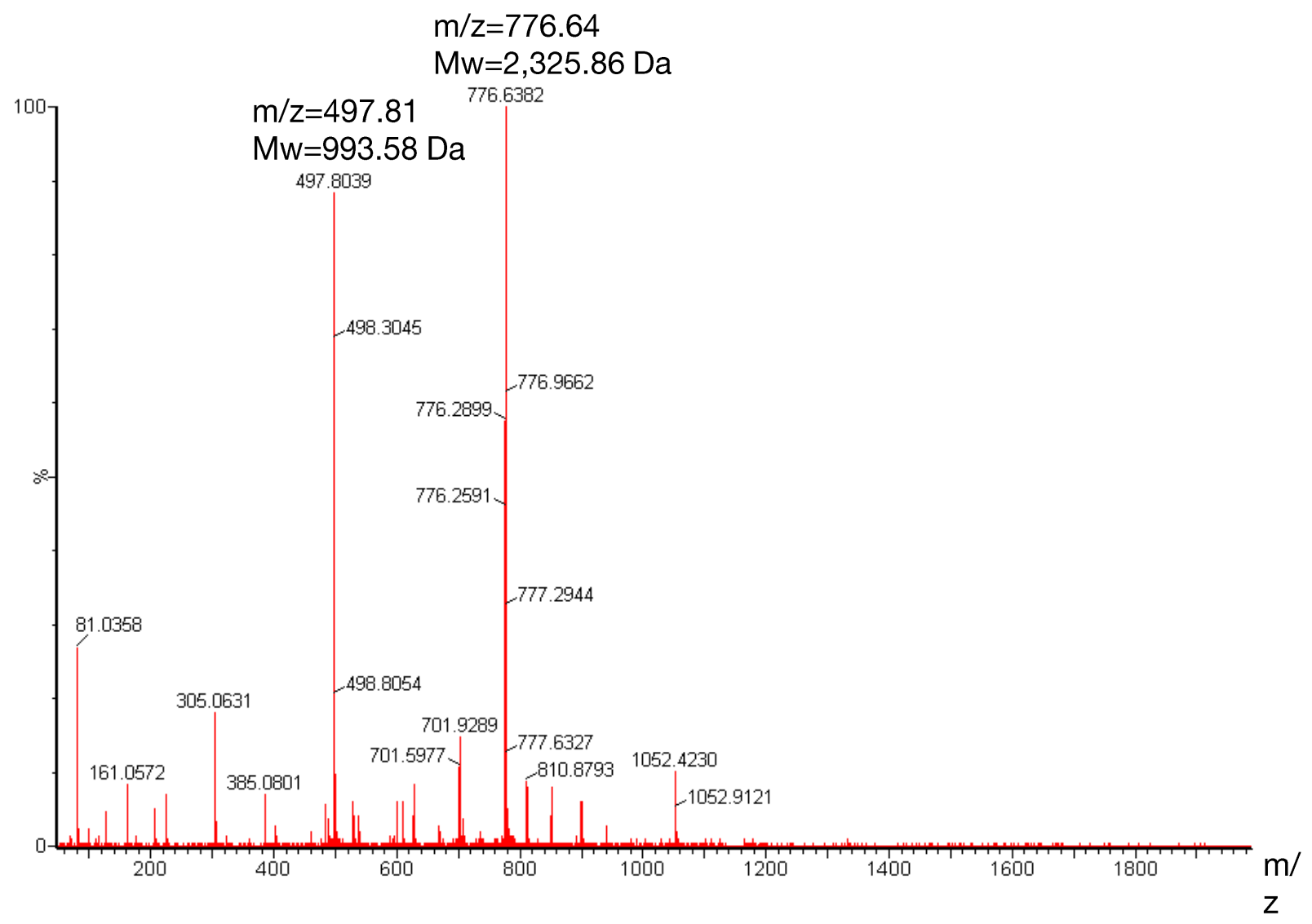

Supplementary Figure 9

Spectrum of MS/MS analysis with the 2,325.86 Da ion $(\mathrm{m} / \mathrm{z}=776.23)$; the $993.58 \mathrm{Da}$ ion $(\mathrm{m} / \mathrm{z}=497.81)$ abundance corresponds to the molecular weight of RIHKTPSR (993.583 Da). Representative result from three independent replicates is shown. 


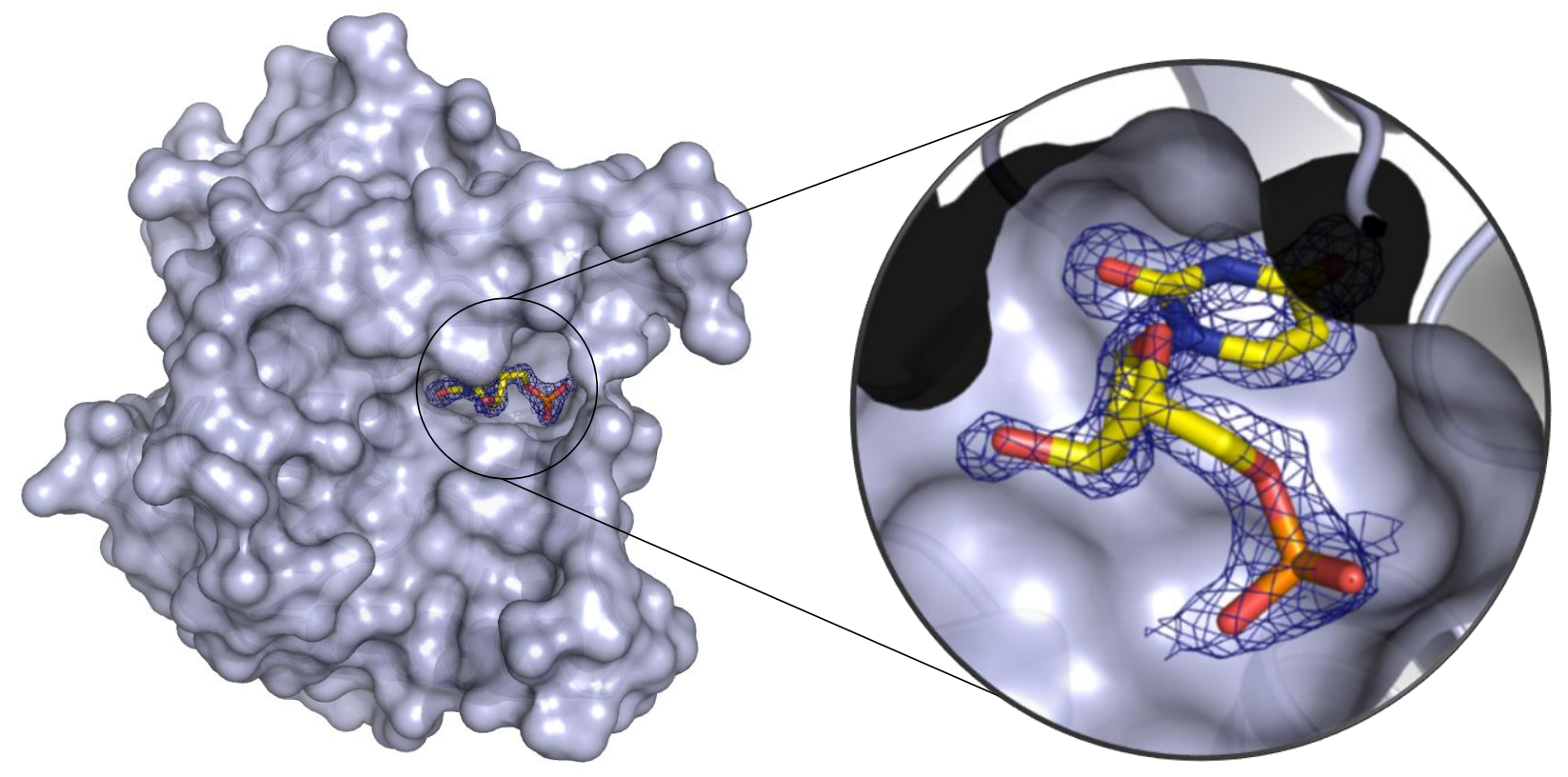

Supplementary Figure 10

Structure of MsmUdgX-dUMP complex. 2Fo-Fc map contoured at $1.0 \sigma$, presented with blue mesh, illustrates strong clear density for dUMP in the active site of MsmUdgX. 
a

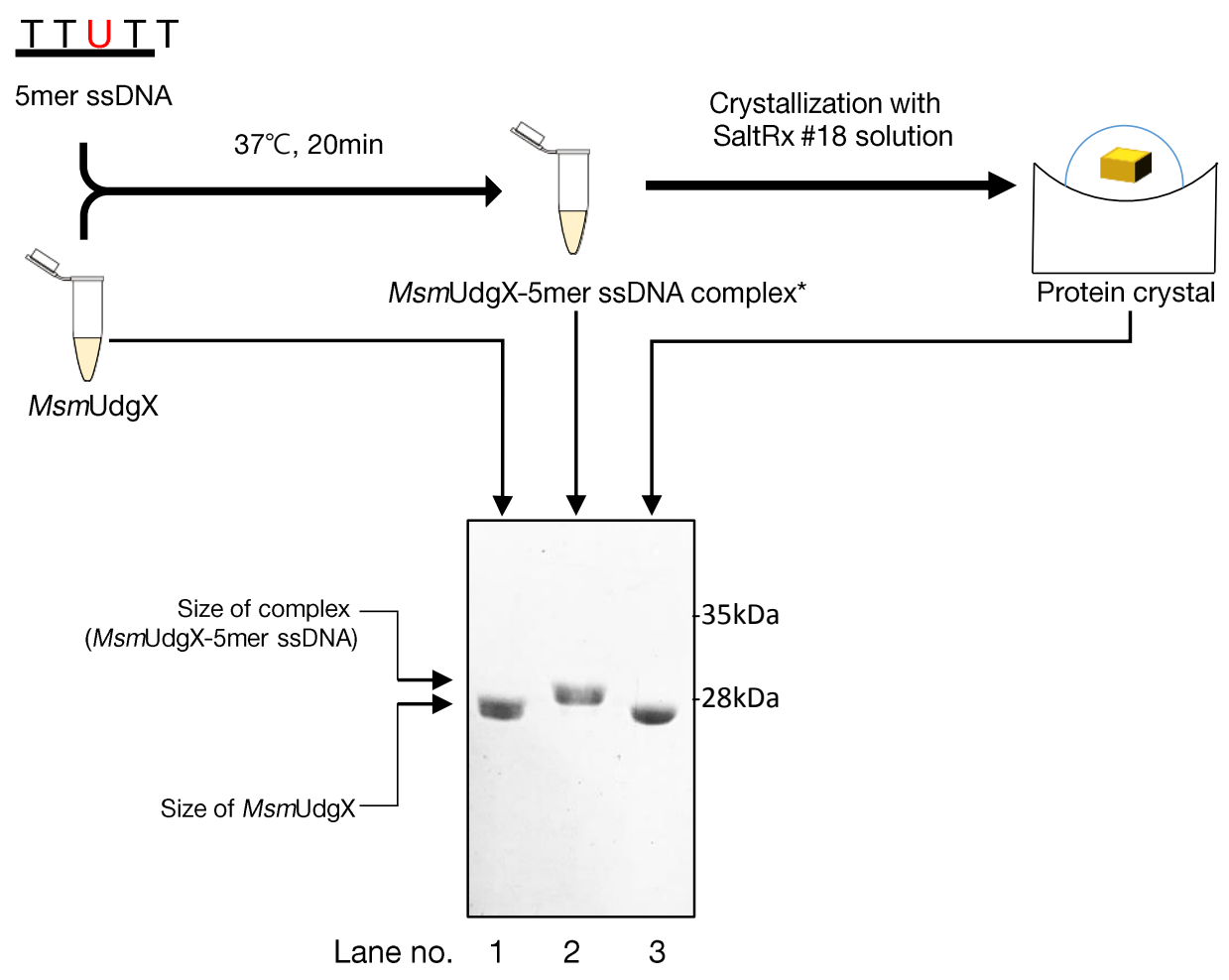

b
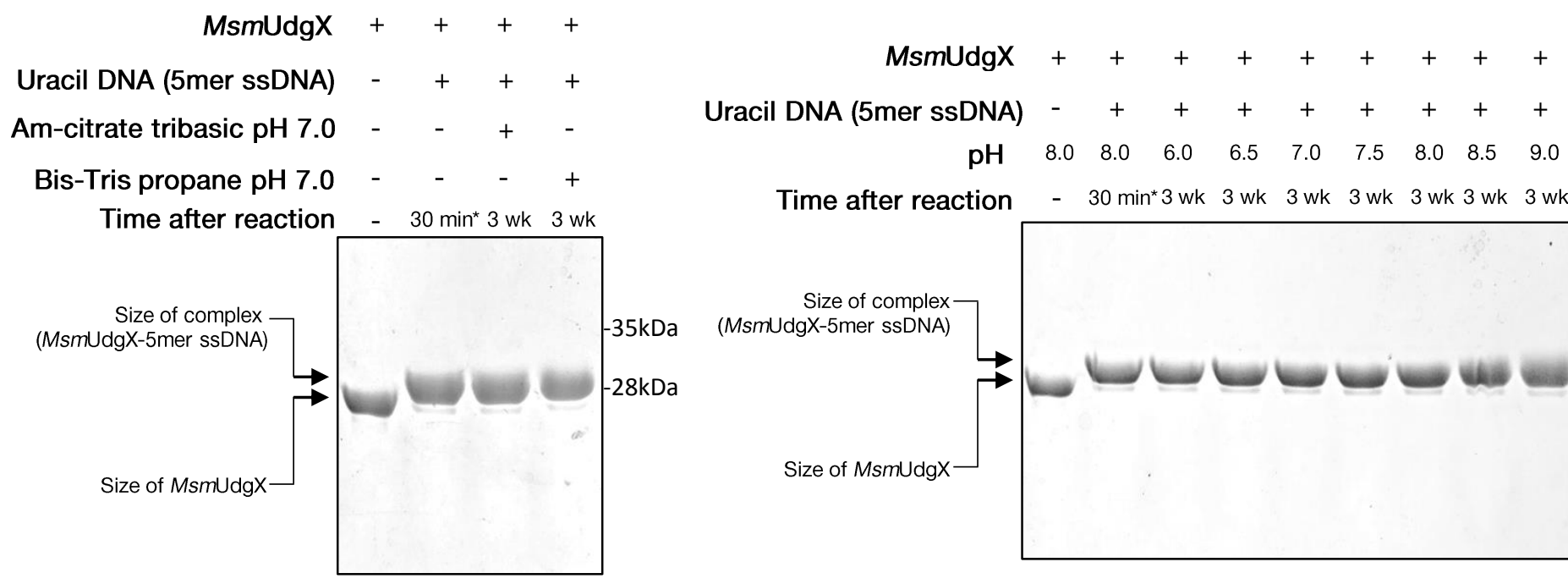

Time after reaction $\quad-\quad 30 \mathrm{~min}^{\star} 3 w \mathrm{k} \quad 3 w \mathrm{k} \quad 3 \mathrm{wk} \quad 3 \mathrm{wk} \quad 3 w \mathrm{k} 3 \mathrm{wk} \quad 3 \mathrm{wk}$

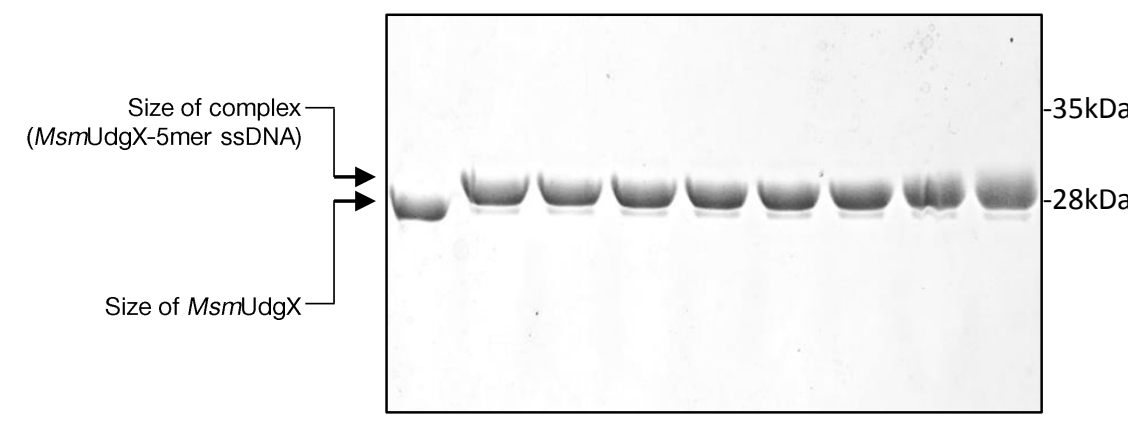

\section{Supplementary Figure 11}

Determination of the status of the covalent bond between MsmUdgX and 5mer ssDNA (TTUTT) in crystals. (a) Electrophoresis of the MsmUdgX protein (lane 1), the mixture of MsmUdgX and 5 mer ssDNA reacted for $20 \mathrm{~min}$ (lane 2), and the protein crystals (lane 3) obtained 3 weeks after crystallization setup with SaltRxI \#18 solution (2.0 M ammonium citrate tribasic, $0.1 \mathrm{M}$ Bis-Tris propane $\mathrm{pH}$ 7.0). ${ }^{*} M s m U d g X$ and 5 mer ssDNA complex were freshly incubated before the electrophoresis. (b) The MsmUdgX-5mer ssDNA complex was incubated in the presence of 2.0 $\mathrm{M}$ ammonium citrate tribasic $\mathrm{pH} 7.0$ or $0.1 \mathrm{M}$ Bis-Tris propane $\mathrm{pH} 7.0$ for 3 weeks in $18^{\circ} \mathrm{C}$. None of the crystallization chemicals resulted in the cleavage of the bond between protein and DNA. (c) Analysis of $\mathrm{pH}$ effect on covalent bond cleavage. MsmUdgX was reacted with $5 \mathrm{mer}$ ssDNA to allow complex formation and dialyzed against the buffers with various $\mathrm{pH}$ ranging $\mathrm{pH}$ 6.0 to $\mathrm{pH} 9.0$ before the SDS-PAGE. At none of the $\mathrm{pH}$, the complex was seen to be dissociated. Each shown panels are representative results from three independent replicates. 


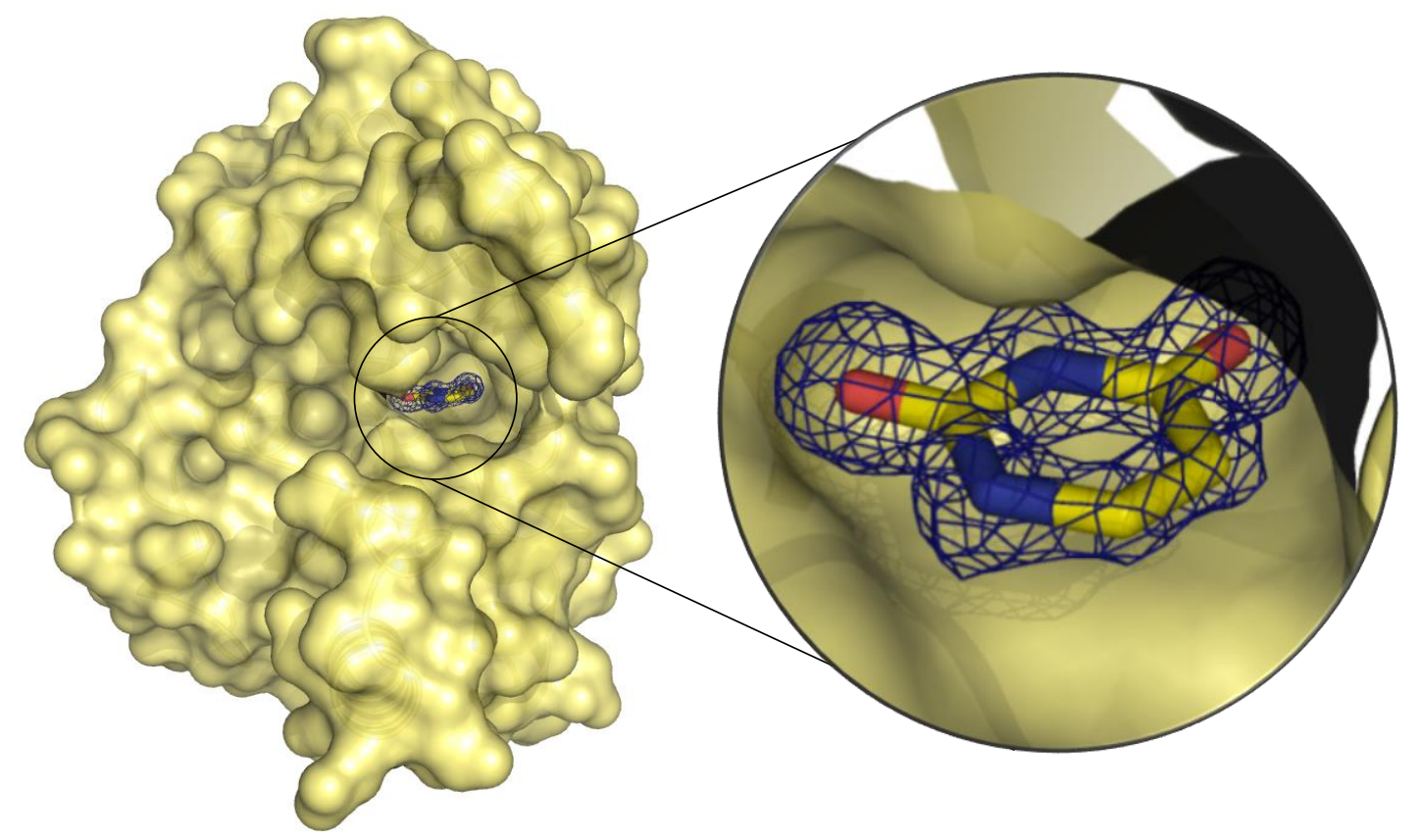

Supplementary Figure 12

Structure of MsmUdgX-uracil complex. Clear electron density for uracil, with the 2Fo-Fc map contoured at $1.0 \sigma$, is observed in the active site of MsmUdgX. Crystal structure obtained from solution of MsmUdgX-5mer ssDNA complex; its formation was determined via SDS-PAGE electrophoresis. 


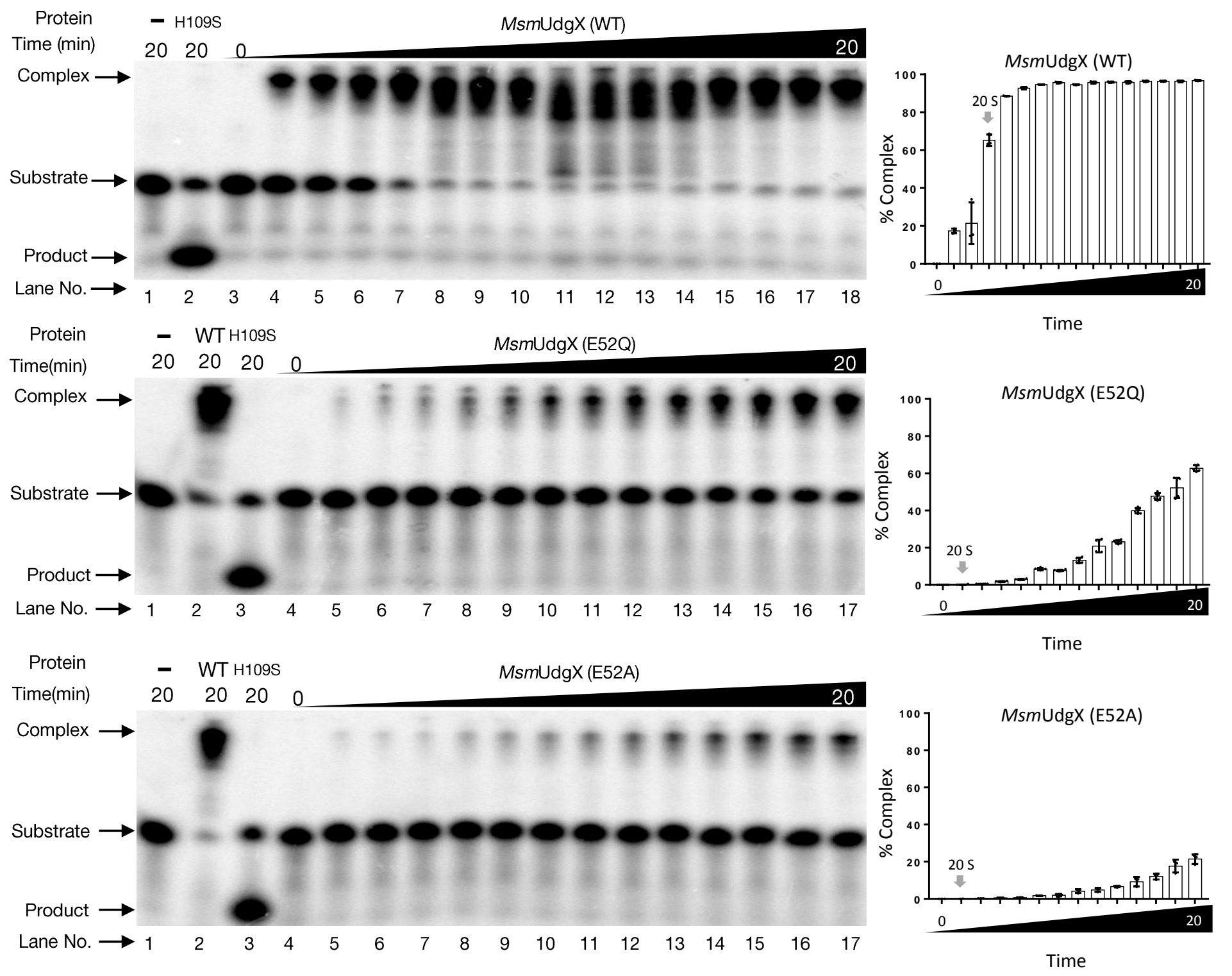

\section{Supplementary Figure 13}

Time course of activity analyses of MsmUdgX (WT), and its E52Q and E52A mutants. Assays were performed with the 0.1 pmol of SSU9 DNA oligomer with $125 \mathrm{ng}(5.14 \mathrm{pmol})$ of proteins at $37^{\circ} \mathrm{C}$ for $0 \mathrm{~min}$ to $20 \mathrm{~min}$. Lanes 3 to $18 \mathrm{in} \mathrm{MsmUdgX} \mathrm{(WT)} \mathrm{correspond} \mathrm{to} \mathrm{reaction} \mathrm{times} \mathrm{of} 0$, $5,10,20,40,60,120,180,240,300,420,540,660,840,1080$, and 1200 seconds, respectively. In the E52Q, and E52A mutants, the lanes 4 to 17 correspond to reaction times of $0,20,40,60$, $120,180,240,300,420,540,660,840,1020$, and 1200 seconds, respectively. Reactions were resolved on $8 \mathrm{M}$ urea PAGE (15\%) and visualized by phosphoimaging. Plots of the complex accumulation against time for each experiment are presented in the right panels. Values for 20 $s$ time points are indicated in all the plots. Each shown panels are representative results from three independent replicates. Data in graphical graphs on right side represent the mean of three independent experiments \pm s.d. 

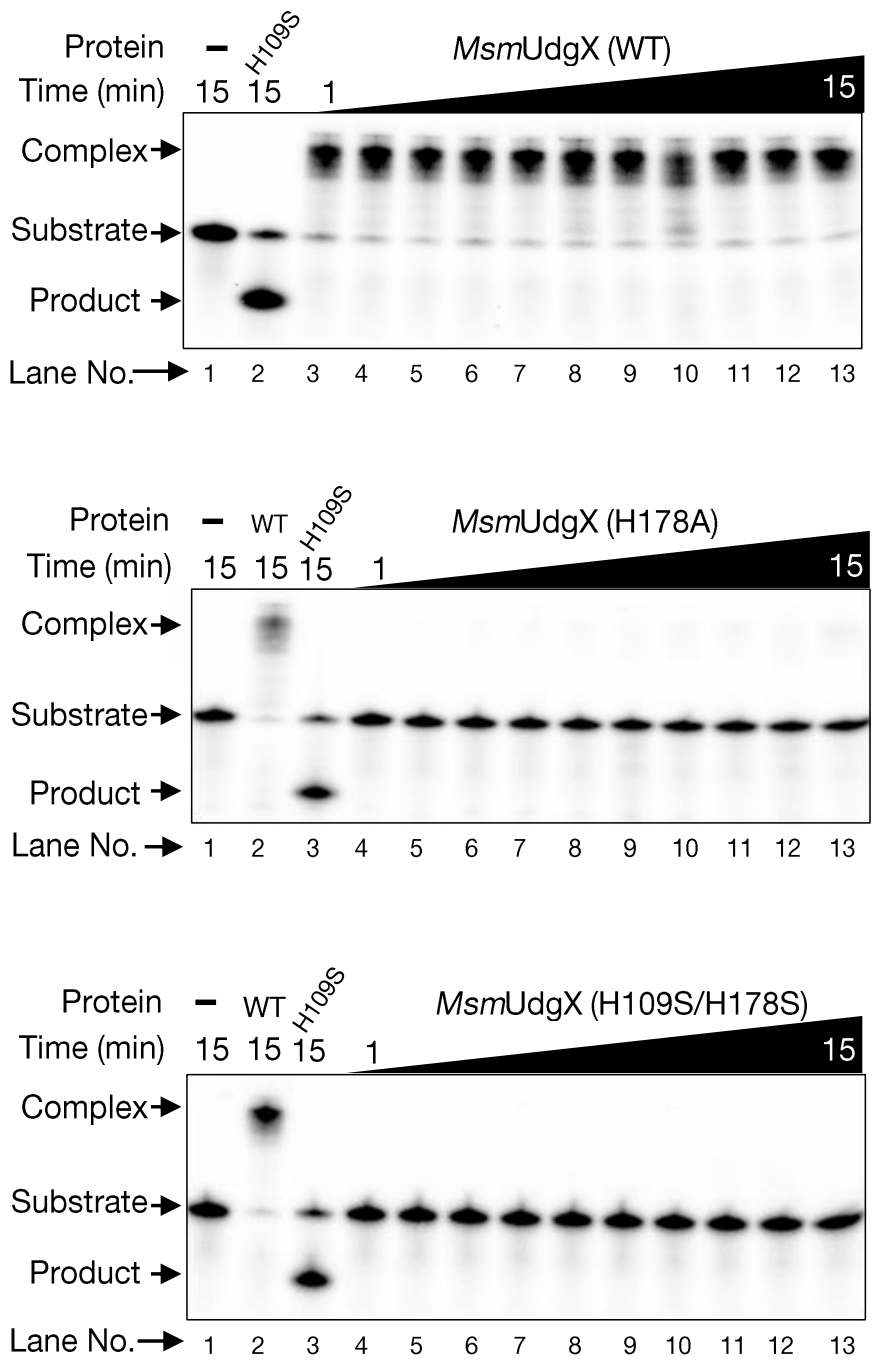
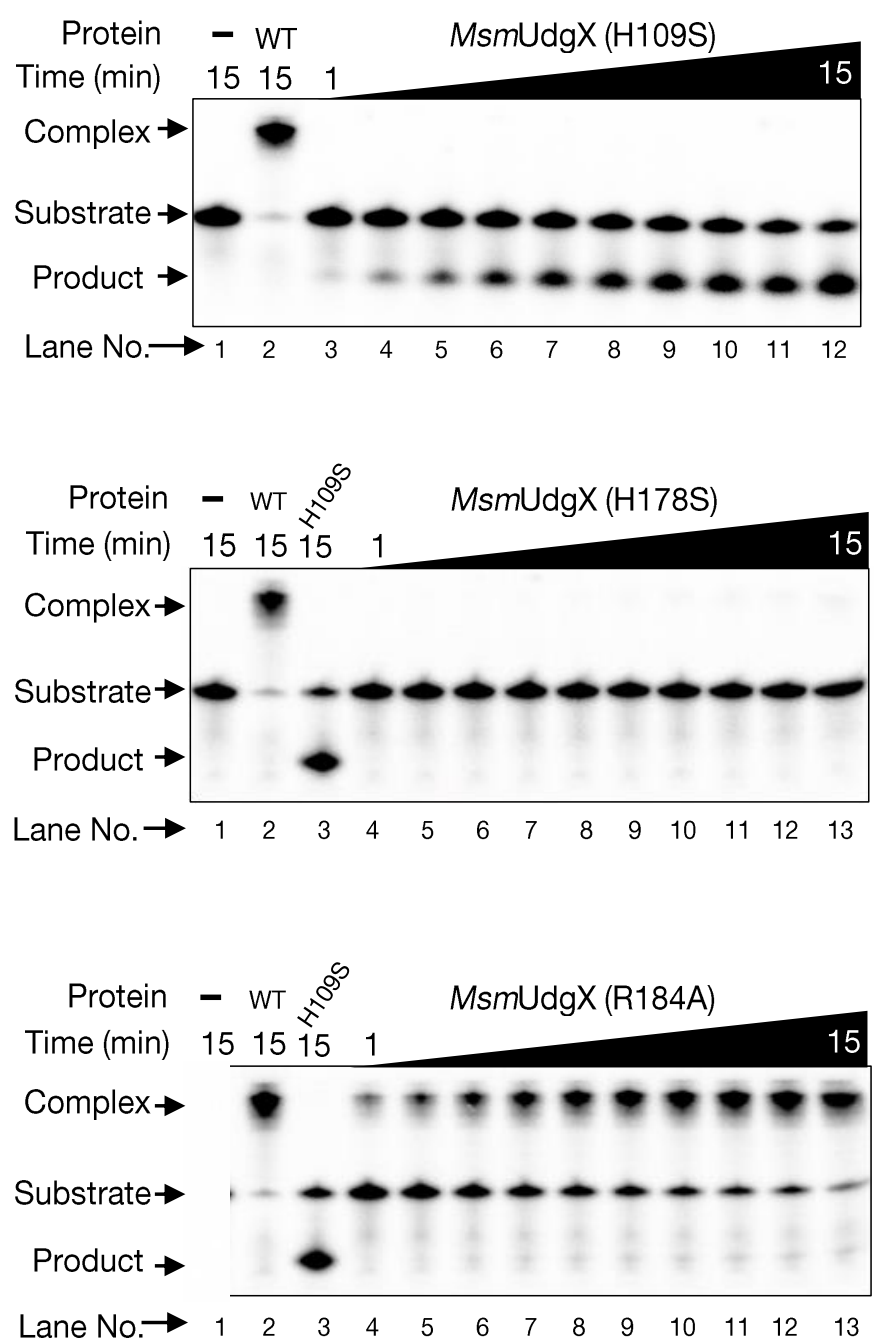

\section{Supplementary Figure 14}

Time course of activity analyses of MsmUdgX (WT) and its mutants. The activity assays were carried out with SSU9 DNA substrate at $37^{\circ} \mathrm{C}$ for $15 \mathrm{~min}$. The reaction times for lanes 3 to 13 in $M s m U d g X$ correspond to 1, 2, 3, 4, 5, 6, 7, 8, 9, 10 and $15 \mathrm{~min}$, respectively. The reaction times for lane 3 to 12 in H109S corresponds to 1, 2, 3, 4, 5, 6, 7, 8, 9 and 15 min, respectively. The reaction times for lane 4 to 13 in H178A, H178S, H109S/H178S and R184A correspond to $1,2,3,4,5,6,7,8,9$ and 15 min, respectively. The reactions were resolved on $8 \mathrm{M}$ urea PAGE $(15 \%)$ and analyzed by phosphoimaging. Each shown panels are representative results from three independent replicates. 


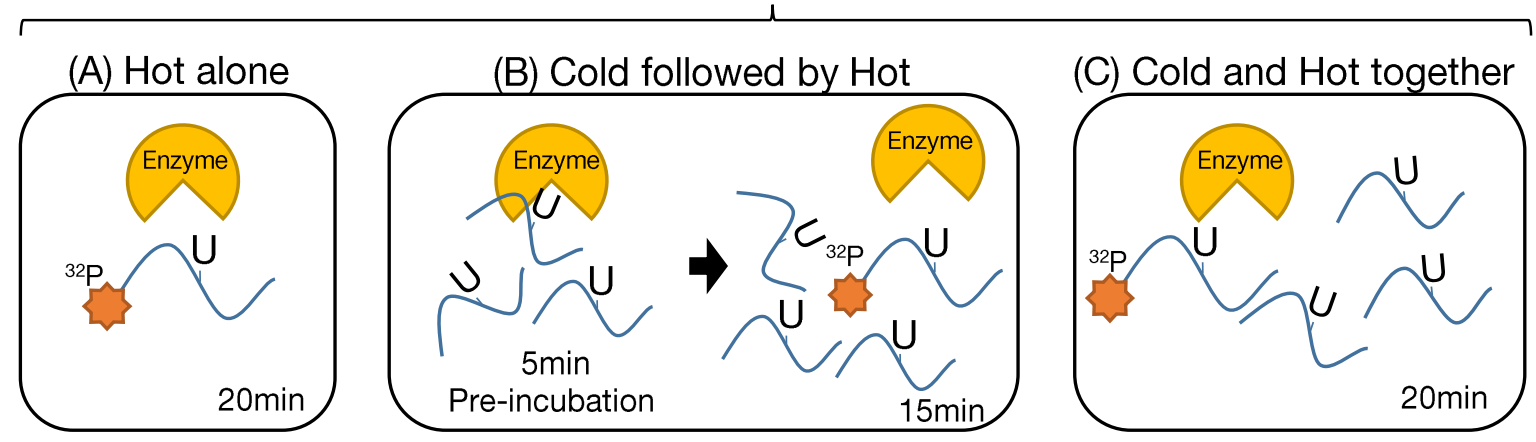

b

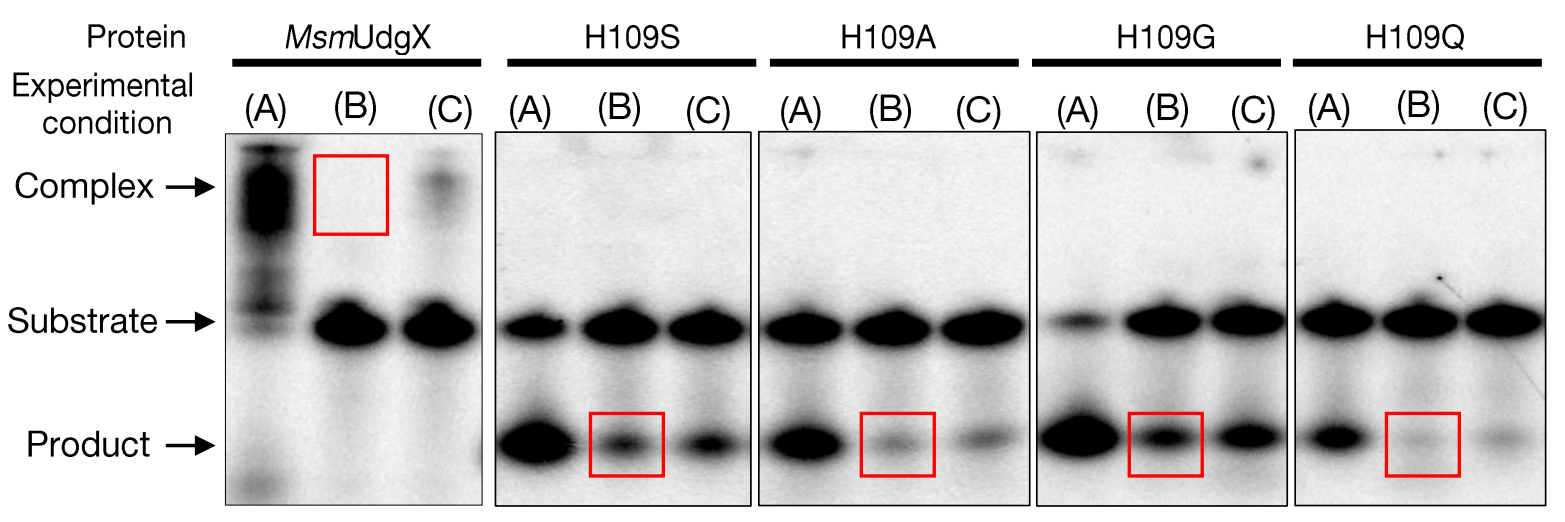

\section{Supplementary Figure 15}

(a) Schematic diagram of the experimental conditions used to determine turnover activity. (b) Turnover activity assays for the wild type MsmUdgX, and H109S, H109A, H109G, and H109Q mutants. Under condition $(A)$, the protein $(0.5 \mathrm{pmol})$ and 5 '-32P-radiolabeled (hot) substrate $(0.1$ pmol) were incubated for $20 \mathrm{~min}$. Under condition (B), the protein $(0.5 \mathrm{pmol})$ was reacted for 5 min with excess of unlabeled (cold) substrate (1 pmol) before addition of 5'-32P-radiolabled (hot) substrate $(0.1 \mathrm{pmol})$ and further reaction for $15 \mathrm{~min}$. Under condition $(\mathrm{C})$, the protein $(0.5 \mathrm{pmol})$, 5 '-32P-radiolabled (hot) substrate $(0.1 \mathrm{pmol})$, and unlabeled (cold) substrate $(1 \mathrm{pmol})$ were reacted together for $20 \mathrm{~min}$. The substrate was SSU9 DNA oligomer. The reacted samples were resolved on $8 \mathrm{M}$ urea PAGE (15\%). Red squares indicate the areas where radiolabeled product/complex should appear in case of reaction with a turnover. No radiolabeled complex was seen under condition (B) for MsmUdgX (WT) suggesting no turnover. However, radiolabeled product was seen under condition (B) for the mutant MsmUdgX proteins, suggesting turnover. Representative result from three independent replicates are shown. 
a

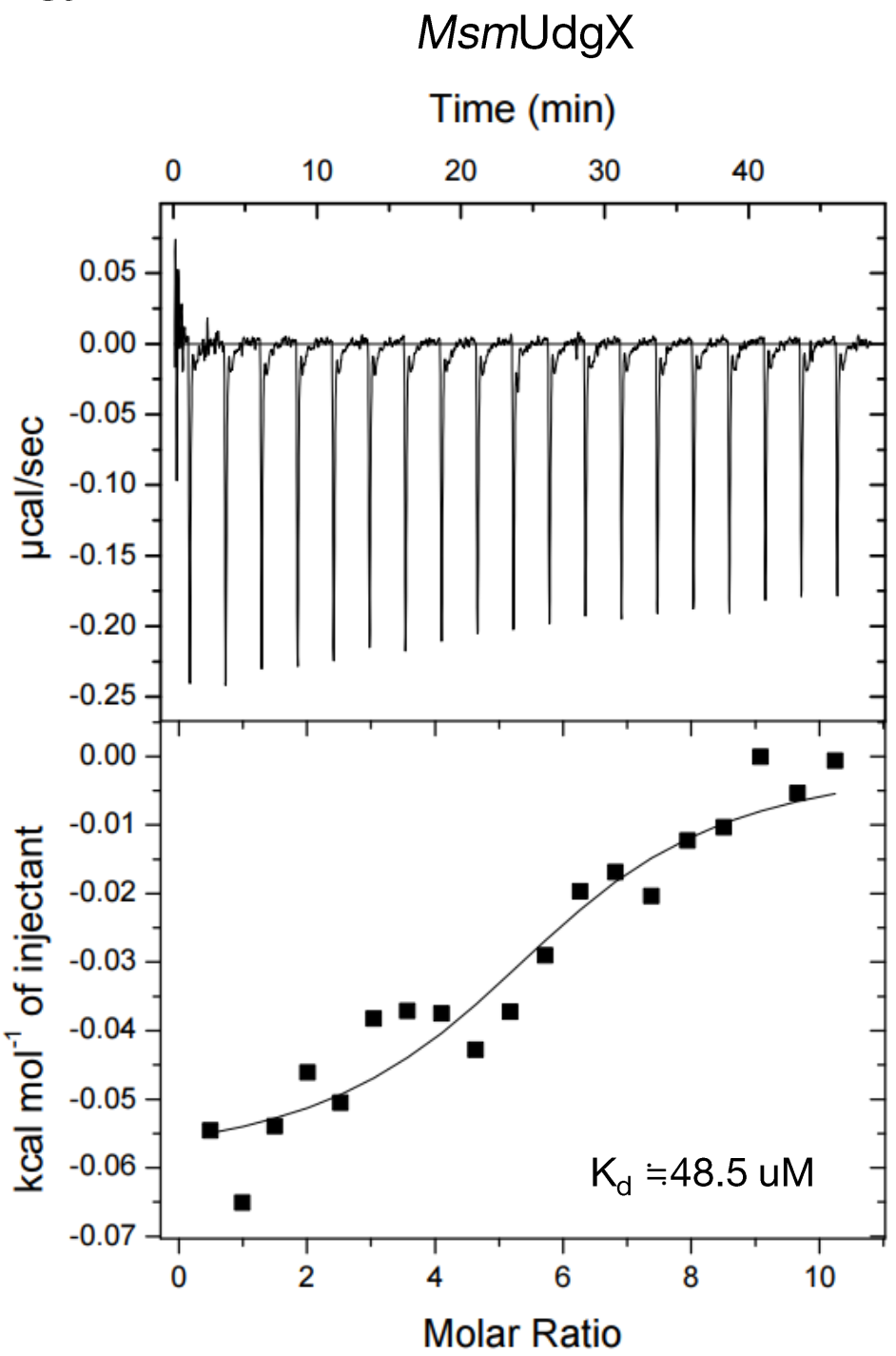

b

MsmUdgX H109S

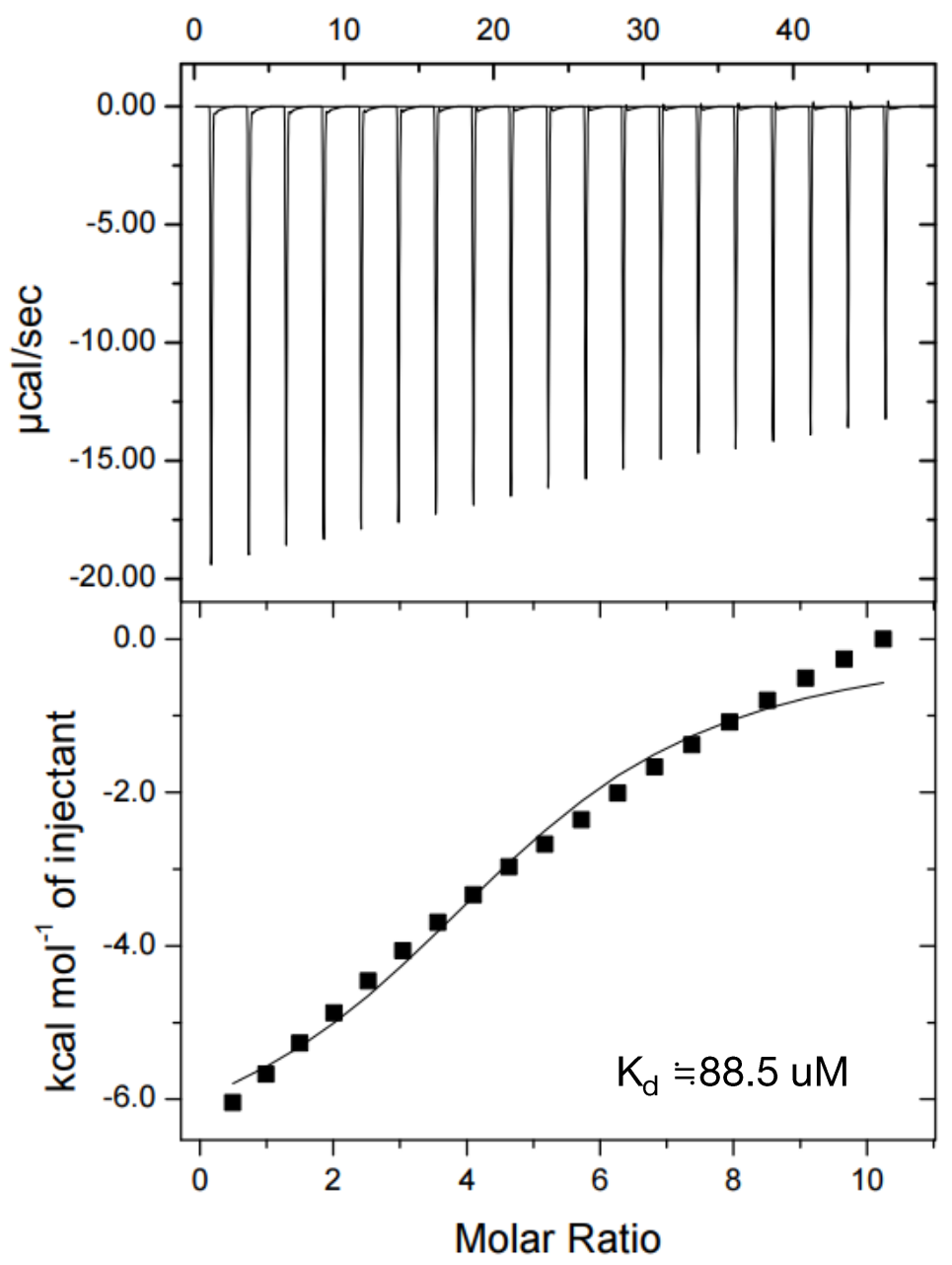

\section{Supplementary Figure 16}

Isothermal titration calorimetry (ITC) profiles for MsmUdgX (a) and H109S mutant (b) to uracil base. The upper panels show the raw data and the bottom panels show integrated heats of injection and the best fit with MicroCal Origin (ver 7.0) software. Representative titration images for three independent replicates are shown. 

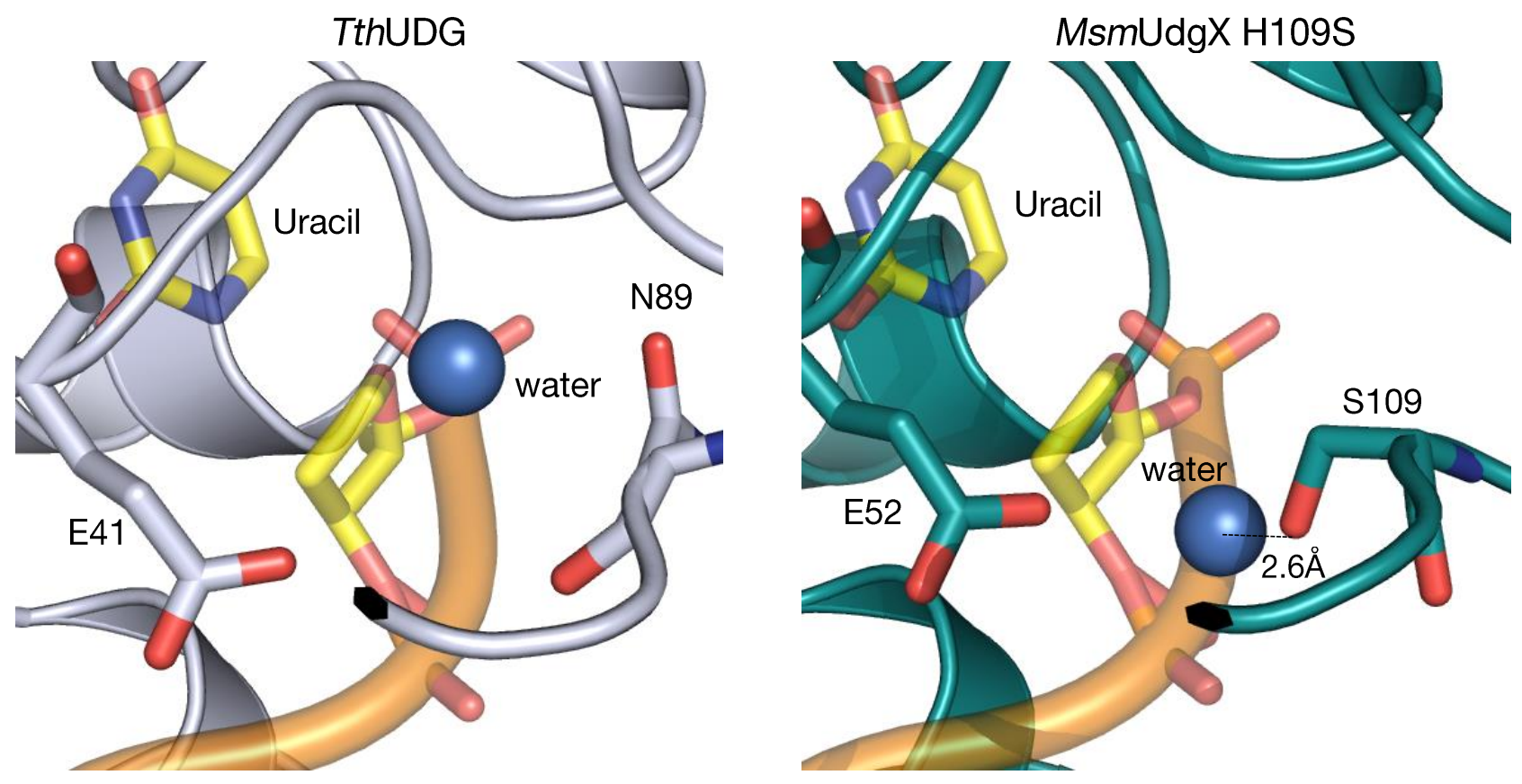

Supplementary Figure 17

Water molecules in the vicinity of general bases in the active site of TthUDG (left) and MsmUdgX H109S (right). Hypothetical position of uracil DNA based on MsmUdgX-5mer ssDNA complex, presented as transparent yellow sticks. 
Figure 5a

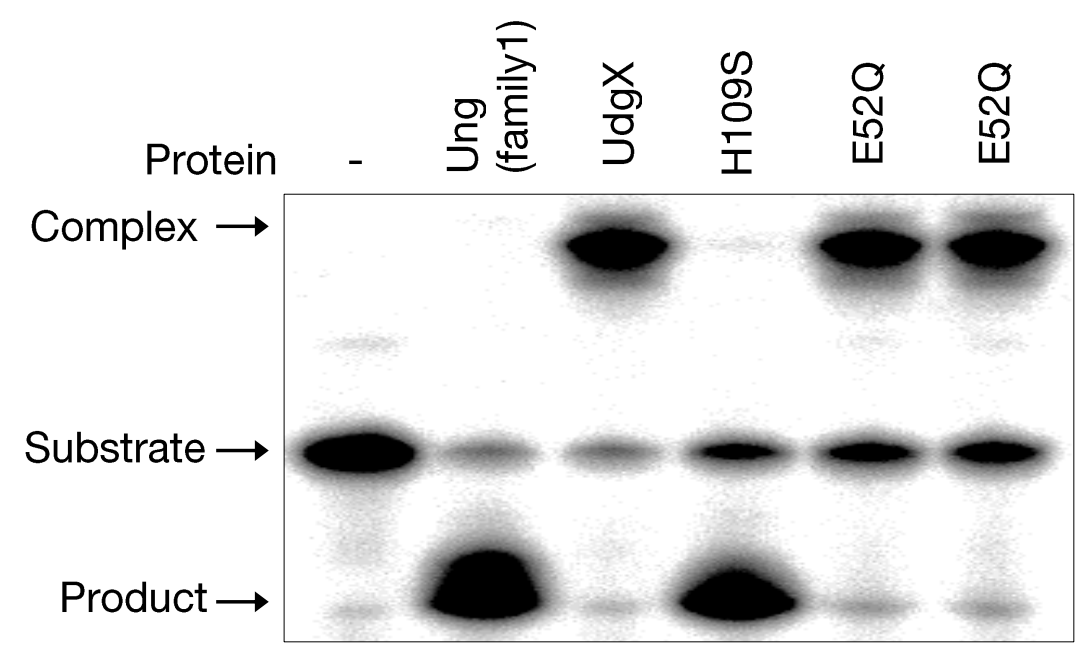

Figure 5b

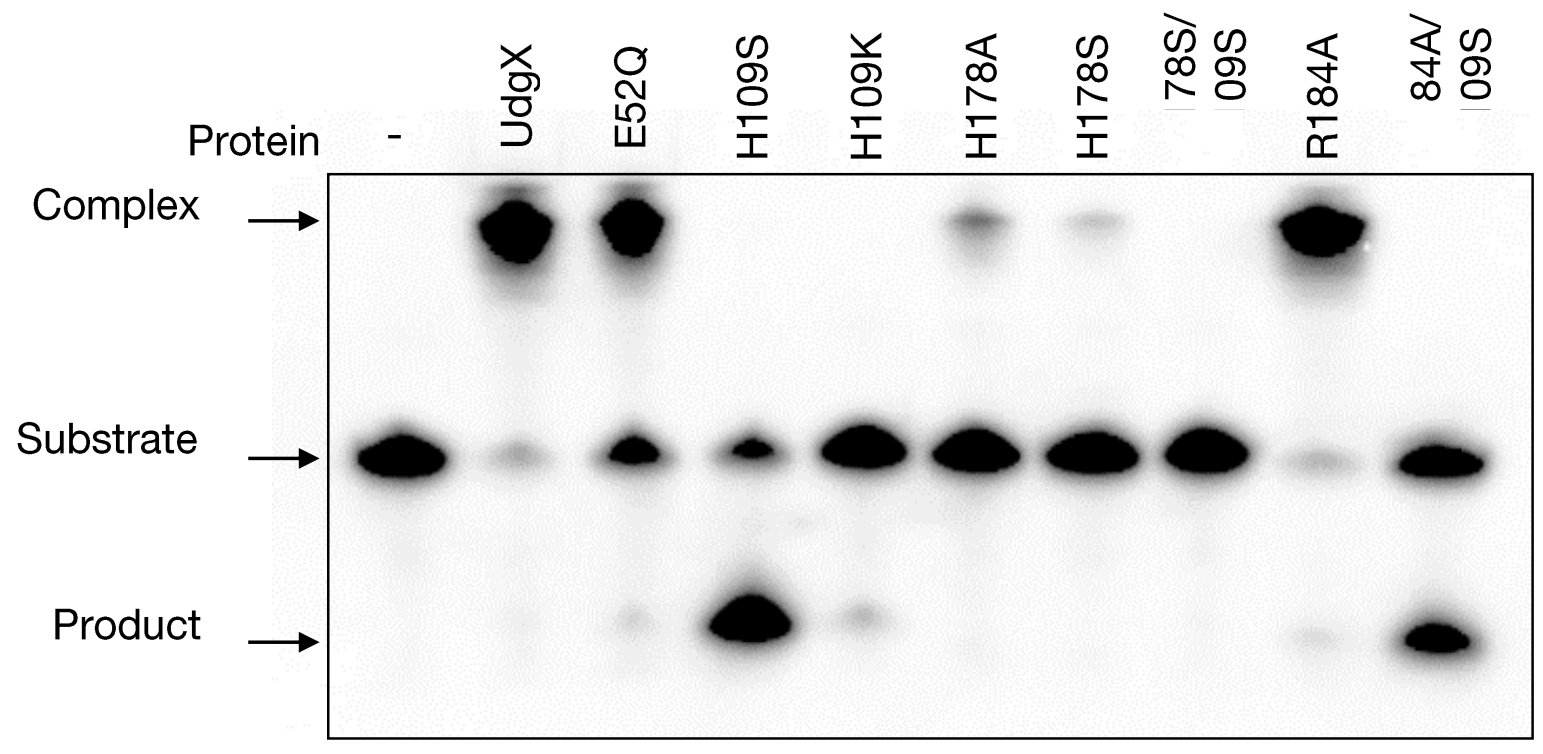

Supplementary Figure 18

Uncropped gel of Fig. $5 a$ and b. 